To appear in: K. Toohey, S. Smythe, D. Dagenais \& M. Forte (eds.). Transforming Language and Literacy Education: New Materialism, Posthumanism, and Ontoethics

\title{
Exploring affect in stop frame animation
}

\author{
Gabriele Budach, Dimitri Efremov*, Daniela Loghin*, and Gohar Sharoyan* \\ *Student authors
}

\begin{abstract}
The text explores affect as it unfolded for Master students, co-authoring this article, while engaging with personally meaningful objects, making their first animation movie, and reflecting on this process in the light of new materialist theories. The text is an experiment, emerging from a collective process of living animation making, and intensely discussing, co-thinking and cowriting about this experience. The text attempts to make tangible this complex process, and it aims to share with the reader the potential of animation making as a source of affect, emerging from a temporary assemblage of people and things joint in co-creation and co-agentive collaboration, driven by affective intensities. It aims, furthermore, to recommend animation making as a powerful tool to put in motion learners and learning about materiality, time, space, and our connections with things and people, spurred by affect as a driving force that pushes us towards discovery. The text ultimately seeks to propose an approach towards learning and understanding literacy that takes impetus and grounding from the forces of living, open to the unforeseen and unpredictable, and based in processes of immanence, emergence and movement, rather than in stasis and pre-meditated design.
\end{abstract}





\begin{abstract}
About this text
Developing this piece of work has been a collective endeavor, which unfolded as a meandering path rather than a straightforward journey, full of discovery and surprise, filled, at times, with moments of hesitation, uncertainty and frustration, and, at others, with feelings of energy, excitement, and deep connection. We see it, and hope Deleuze and Guattari might agree, as a process of 'becoming', which is still ongoing and 'not yet' fully known (Spinoza 1995, cited in Gregg \& Seigworth 2010: 3). When we started, we had no previous experience of working together on a project like this, of thinking and discussing intensely as a group, of giving shape and substance to ideas, of articulating experience, difficult to put into words, and of producing and organizing text collaboratively, about an experience, that was shared and yet individually different. From the start, there was no concrete plan or pre-meditated path along which we would be going, no image of what the finished product would look like, nor any set of rules guiding our design process. Design emerged as we moved forward, talking and exchanging about our experience, immersing ourselves into readings about affect, responding to the ideas of others, input and ways of seeing, feeling and thinking, as they became apparent and gained importance as forces shaping the process and unfolding within a timespan of seven months.

All that there was at the beginning, lied in our shared enthusiasm for a learning experience we all had gone through and that we thought had been extraordinary and captivating to an extent that we wanted to explore, learn more about it and share it with others, trying to communicate what had us affected so deeply. Our trust to believe in this project emerged from the intensity of our experience that had us bonding as a group, stronger than before, and from trusting in the process that laid ahead of us.
\end{abstract}


It started with a Summer School on "Multilingual Identities in the Making”, organized by the 'Master in Learning and Communication in Multilingual and Multicultural Contexts' at the University of Luxembourg in September 2018, at the end of the first year of the program in which we were all involved. Under the guidance of filmmakers and digital artists, Bo Chapman and Zoe Flynn, from Salmagundi Films London, we joined a weeklong workshop on 'animating objects'. Setting out to investigate 'identities in the contact zone', this involved exploring a personal meaningful object, which each participant was invited to animate. This required hands to manipulate the chosen object in front of a camera lens, using a tablet, mounted on a tripod, and fitted with a stop motion app installed on it.

Looking back, we agree that animation making is an extraordinary field of experimentation with important pedagogical potential. Some of the reasons for it, as we see them now, we will begin to explore in this paper. To start, 'animating objects', the way we did it, taught us something new, exciting, and important, we would describe as the power of affect. Working in this way has been a deeply affecting experience for us, resonating with what Spinoza (1959) has called 'affectus', the bigger or lesser modification of the mind or of the body, either taken in isolation or together. 'Affect', which Deleuzian-Spinozan-inspired work describes as the capacity 'to affect and to be affected' (Gregg \& Seighworth 2010: 2), has been something we felt or perceived in manifold manifestations during the animation making process. However, making sense of what we sensed proved equally, intriguing, challenging and difficult. Insights about our experience we were able to distill so far, we hope to share with the reader in this paper.

Animation making unfolded, second, as a process, none of us could have anticipated, predicted or pre-designed. It seemed governed, to a significant extent, by forces that laid beyond our control, still producing something new, surprising, unique and, as we felt, very valuable. 
What emerged seemed less the product of our own will alone, but shaped by all the elements involved in the process, human and non-human; objects, parts of technology and furniture, stories emerging from the concrete actions performed in situ, or memories mixing in with images produced in front of the camera lens. All these elements became part of co-creating movement, the motions, gestures and actions involved in animation making. While animation can be done, these days, entirely on a computer using specific software, we opted for the analog procedure of literally moving objects manually, in tiny increments, step-by-step, in front of a camera lens. This involved placing an object - taking a shot - moving the object a tiny bit - taking another shot - moving the object yet again - taking another shot - and so on.

In this way, animation making revolves primarily around the co-production of movement, a process being oriented towards movement rather than stasis (Massumi 2002). In this process of co-producing movement all elements, human and non-human, are endowed with a role and a place engaging with each other in intensive inter-play. This process, ultimately, produces an animation and exerts a deeply affective and transformative power on all entities involved.

The fascination for us lied in the fact that each of us felt affected, but experienced the animation making differently, bringing different ideas, connections, sensitivities and abilities to affect and to be affected to the task, and creating very different things from it. This is what makes animation, in retrospect, such a rich terrain for exploring and understanding about affect and processes of learning as fundamentally rhizomatic. Reminded of the image of a rhizome, used by Deleuze and Guttari (1987), we felt that the process resembled that bulb plant whose roots spread out into all available space and connect with other roots forming and becoming available for connection at particular moments in time. In our case, such possibilities for connection were offered by the object - what it could do -, the film setting and the possibilities it 
provided, our imagination, the stories, already thought and present in our head, and those emerging from the immediacy of animation making. This space, made up of different elements whose configuration and abilities to bond or disconnect changed throughout the process, looked different for each of use. While variation is a very common feature in any learning, interpretation and problem solving, we felt that the openness and freedom of choice and exploration we experienced throughout the process added to the range and shape of difference showing in our animation pieces.

\section{Preparing for the Summer School and getting started}

Our process began with reading a text - the greatly inspiring 'Arts of the Contact Zone' by Marie Louise Pratt (1991). It helped us selecting an object that would embody a 'contact zone', for each of us, individually. Dimitri selected a music player, the object longest in his possession, connecting him with the world when traveling for him was difficult. Daniela selected a bookmark given to her by her grandfather at the age of four that spurred her imagination about books and her interest in reading - at a time, when that ability for her was 'yet to become'. Gohar chose a carrot, called gazar in Armenian that had gained some importance for her recently bringing to the fore the relatedness of the Armenian language to a wider range of other languages and cultures. Selecting an object proved very easy for Dimitri and Daniela who decided almost instantaneously while reading the text. It took more time for Gohar to decide on an object that would carry important meaning for her. We see how from the very beginning - starting with the reading of the text - the space we would be sharing during the Summer School was bound to unfold as a "simultaneity of stories-sofar” Massey (2005: 24) with the prospect of moving, evolving and transforming during what was yet to come. The space, as it was building even before we met for the Summer School workshop, became shaped by our individual interpretation 
of the reading, the choice of our object, the stories we shared with it and the intensity with which we felt bonded to both, the objects and the stories.

Situated within a 'book space’ (Lankshear \& Knobel 2006) initially, the activity turned quickly into a 'bloom space’ (Gregg \& Seighworth 2010) where affect would reign, with the text moving gradually, but rather quickly in the background, out of sight, as individual projects started to unfold between hands and moving objects in front of a camera lens. Resonating with scholarly critiques of the 'multiliteracies' approach proposed by the New London School (1996), the process took us away from doing literacy in ways that center on text (Lankshear \& Knobel 2006) towards a world of literacy that is much broader than the materiality, organization and (sequential) structuration inherent in texts, and the affordances required to (re-)produce them. While our starting point was a text, the final product and process of production were not textual, or at least not primarily. Making an animation, as it turned out, did, indeed challenge our ideas about how to engage with texts, textual planning and production, as our habitual and rehearsed ways of going about text design seemed, to some extent, problematic. Recourse to existing (textual) grammars, their rules and modes of application, for instance to structure a story line failed, or were at least fundamentally challenged, by a process that seemed to be guided by different forces, that, unlike a mindset applying rules, appeared to defy predictability and structured planning. The aim of our exploration is therefore not to suggest another model or set of rules for making ‘a good animation’. On the contrary, we learnt to appreciate the possibility to work without a matrix of grammar rules and to evade the corset of static and fixed positions, as they underlie ideas of design, as theorized for instance in systemic functional grammar (Halliday 1978, Halliday \& Matthiessen 2014; for a fuller discussion, see Leander \& Boldt 2013: 31). In such a context, design tends to be understood as a pre-planned, systematic approach towards 
creation that is based on principles attached to functions and values within a system. In creation, seen in this way, elements of a system are (re-)combined according to rules that can be known and taught. Hence, creation can be imagined and anticipated, based on a deep knowledge of the system and its modes of operating. Compared with our experience of animation making, such an anticipatory imagining failed, or was at least difficult, as the design seemed to be suggested by the process, and less by a pre-determined idea of a pre-conceptualized possible product. In contrast, we felt that animation work was leading us along an unknown path, that was destabilizing at times, but ultimately liberating, as it was not "projected toward some textual end point, but [unfolded] as living its life in the ongoing present, forming relations and connections across signs, objects, and bodies in often unexpected ways. [...] generating intensity and the excitement of emergence”. (Leander \& Boldt 2013: 25)

In retrospect, we agree with the critique suggested by Leander and Boldt (2013) who describe the effect of models that pre-structure creation, learning and, in their context, literacy activity, as a “domestication [of learners and learning] ${ }^{1}$ that subtracts movement, indeterminacy, and emergent potential” (24). What made our experience unique and valuable for us, resided in precisely these elements: movement, indeterminacy and emergent potential.

When the Summer School began, we first shared our objects and stories. We agree with Thiel (2015) who says that “materials offer new reference points” (129), and sharing stories around materials and objects to which we feel affectively and emotionally connected "enable [...] to create listening spaces for students [...] that can shift understandings of communities, identities, and neighborhoods" (123). In our case, the topic in focus were the challenges and opportunities of living in contact zones, where different cultures meet and mingle. Sharing the

\footnotetext{
${ }^{1}$ Addition by the authors.
} 
objects and listening to the stories, affected some of us more deeply than others. Some could recognize themselves in the stories others told. Others felt less engaged by the exercise and turned rather quickly towards their own object eager to explore its potentialities. This pattern of some connecting more strongly than others with particular aspects of the general 'assemblage' of the classroom should remain present throughout the entire process. How these dynamics unfolded, in varying ebbs and swells of intensity, we are attempting to sketch, at least in a very broad manner, in the following sections of the paper.

While all being seated in the same classroom - on chairs in a circle, holding our object in hand, surrounded by other stuff, technical equipment, paper, pencils, props for filming - each of us started entering into their own individual 'assemblage' around animating a personal meaningful object. Using the term assemblage here, we refer to what Cole and Ringrose (2013) call the 'temporary grouping of relations' that became established at that particular instance of animation making, and that dissolved again after the project was finished. The assemblage included mobile objects, technical apparatus, locations and pieces of infrastructure, such as the focus object of our choice, the camera with app and the spot for filming, inside or outside of the classroom. The forming of the assemblage, and how we experienced it, unfolded for each of us individually. Variation derived from the (already existing) relationship with the focus object, additional materials, the environment and filming setting, and people intervening in the process. All elements interacted as parts of the assemblage and determined how conversation unfolded between the different parts, how affective intensity built or loosened in the flows of 'swells and ebbs of intensity' (Greg \& Seighworth 2010). In what follows student co-authors share an individual reflection on how they experienced the process of animation making. We consider 
these narratives our primary data, that emerged from the recollection of experience built on readings about new materialism.

\section{Rethinking our experience after reading and discussing about 'affect'}

\section{Dimitri}

At the same time as attending the Summer School, I was also actively involved in another project. Thus, in the mornings, I was working on my stop-motion film, and in the afternoons, I was participating in another project, which was a youth exchange.

The activities were the opposites of each other: the youth exchange was a fast-paced, active social event, while the Summer School project was slow, monotonous, almost menial but at the same time very intimate. Given this opposite nature of the two projects, I began to treat my filmmaking time as “me” time, the time when I can relax, focus on myself, and isolate myself from the world around me. The monotonous nature of the work on my film also made it therapeutic for me.

The Summer School project was supposed to be personal from the start, since the idea was to work with a personal object. The selection process to pick an object I would subsequently work with was quick and intuitive. I had chosen a music player, the object longest in my possession (over 10 years), and the one that I am still using on a daily basis. I never thought too much into it; from the beginning of my involvement in the Summer School project, I decided that I would go with the flow, and for the whole duration of it. I wanted to try to approach the project from a different, more creative angle.

In my opinion, the creativity process should not be tamed by rules and restrictions. I was not very engaged into the preparatory stages of the project, when all the participants were sharing their ideas, talked about their objects, and thought out loud about the way they planned to 
approach the work on their film. I wanted to have a very personal experience; in retrospect, I feel that I purposefully restricted my communication with everything and everyone around me for the duration of the Summer School.

I was waiting to jump into the creative process. I skipped the scenario-creating stage completely (I am now struggling with remembering the word that was used to describe the 6panel format we were supposed to use to compile our scenarios). Once I gained access to the filming equipment, I set the "stage” and began working.

To reiterate, throughout the whole project I was going with the flow. I did not think my next steps through, I did not analyze what I was doing; even more, I ignored the urges to structurize my efforts. In my everyday life, I am an organised person, I think ahead, I strategize, I plan, because at the current stage of my life I have to. But, in the scope of this project I did not have to do it. This is the main difference in the angle that I took for this project.

Another decision that I made dealt with my use of materials. I purposefully did not introduce any external objects to the environment in which I was working, except for the music player, which ended up being the centerpiece of the film. I sourced all the other materials from the room in which we were working. In retrospect, this way I was trying to establish a more meaningful communication between the main object (the music player), myself and the environment around us.

In my selection of materials, I ended up relying on only a few items, namely some sheets of colored paper, a paper knife, some adhesive tape and colored pens. I like minimalism in art; maybe that was the reason behind my selection of objects. The other reason could have been in me trying to attempt to create a more meaningful interaction between the few objects that I used. A metaphor that comes to mind is a party with a room full of people: everybody is talking, so the 
level of noise in the room is very high; one cannot expect to create a meaningful relationship with another person in these conditions. However, if the room is occupied by a small group of people, the likelihood of the development of deeper relationships is much more likely.

I isolated myself from almost all human contact while working on my film. The state I was in was reminiscent of a trance; I did not want anyone to interfere into my communication with my object. I refused help and guidance from the leaders of the project; my interaction with other participants was minimal, even though we were all working in the same room. I enjoyed that.

I also enjoyed the tangibility of the work that I was doing. The monotonous, tactile movement of an object ever so slightly, taking a picture of the scene, another slight rearrangement of the scene, another photo... The process was very soothing; it also felt meaningful. I was talking to my scene, and it was talking back to me - and, sometimes, it was talking back at me as well. It was a negotiation, a live discussion, a debate with no pre-arranged roles, assigned opinions or moderation. It was equally exciting for everything and everyone involved to see where all this was going. All the decisions were made instantaneously, like the arguments that one comes up with in a heated discussion on a personal topic.

When it was time to stop filming, I knew it. Even though I did not plan it. It just felt right to stop. The conversation was over. I received cues from the object, from the scene, from the environment, and I responded to them.

I did some very simple editing, with all the decision-making that I did throughout being similarly effortless as during the filming.

What I want to emphasize is that not at a single stage of me working on the film had I thought about the need to show this to other participants at the end of the project. What is more, I 
was very reluctant to show and explain the result to anyone else. To me, the process was the most important part. The result mattered very little to me. It still matters very little to me now. Even elaborating on this experience in the textual format feels unnatural. The beauty of the process was its "unconsciousness”, the feeling of going with the flow, letting go, doing what I felt was right at that particular moment of time.

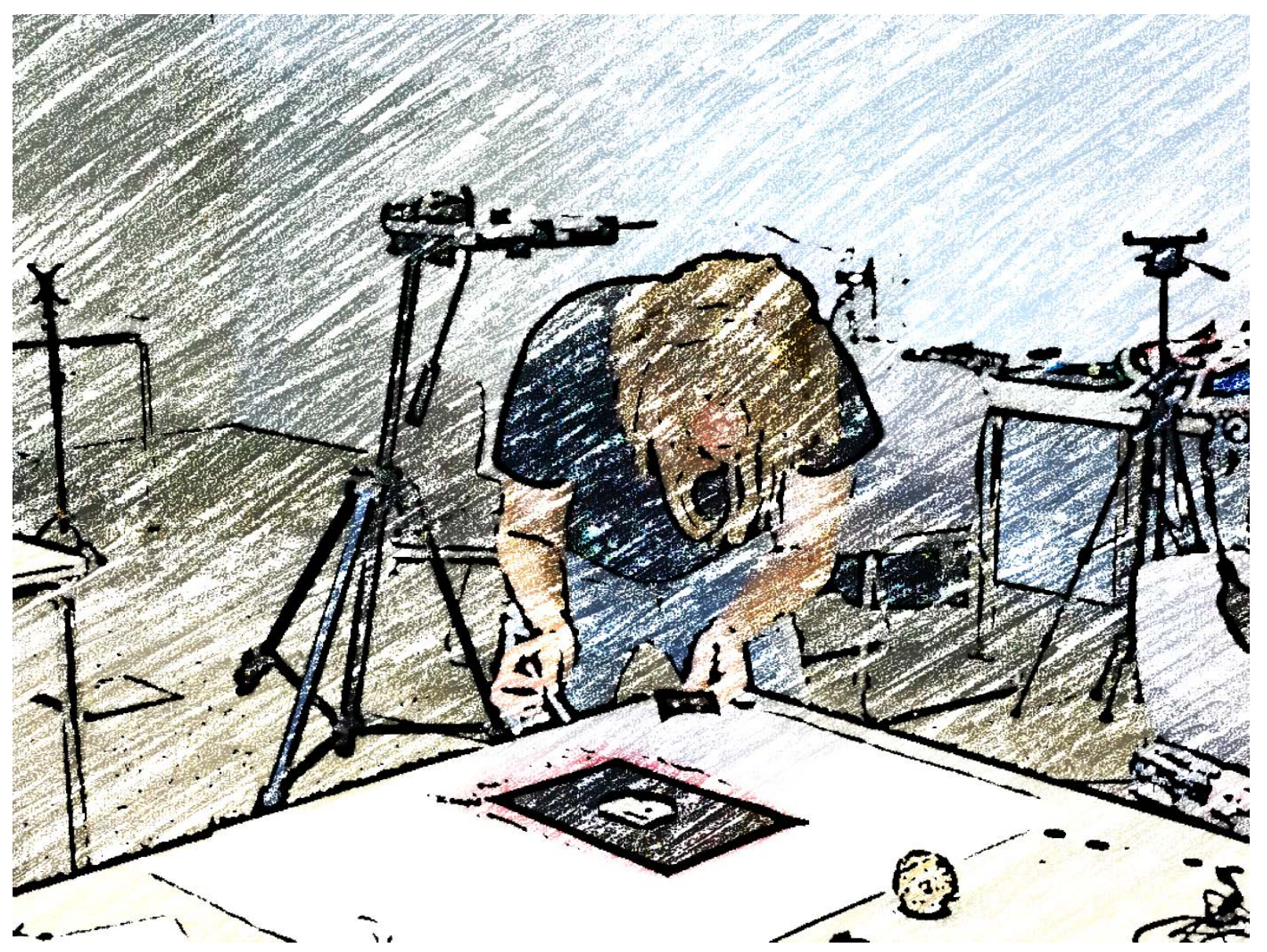

Image $1^{2}$ : Dimitri deeply immersed in conversation and co-creation. To see his movie ${ }^{3}$, please go to: https://vimeo.com/335556188 (enter password: affect1)

\footnotetext{
${ }^{2}$ Copyright of the images in this text is owned by first author. Written consent has been obtained from the co-authors before the Summer School.

${ }^{3}$ Copyright of the films referred to in this text is co-owned by the first author and respective co-authors.
} 


\section{Daniela}

Every object has a story to tell, be it the objects we feel specifically connected to or the ones that end up in our trash bin. However, there are objects in our life that we cherish more than others. Objects that, like the madeleine in Proust ${ }^{4}$ awaken memories and emotions deeply buried within ourselves. Turkle (2007) calls them evocative. The object I chose to animate fits very well in this category.

The bookmark came into my life and I came into its life more than twenty years ago when my grandfather gave it to me. I remember feeling very excited when I received it, and promised to take good care of it, making sure, every day, I did not lose it. Also, it generated a very deep interest in books and I could not wait to learn how to read and be able to place it in my own books. A multitude of stories, relationships and life events have built and strengthened our connection since then and all of them came back to me the moment I brought the bookmark to class. Therefore, it is safe to say that, during the filmmaking, I was highly emotionally engaged.

The choice of the object was relatively easy, and mainly driven by the memories that connected me to it. As my grandfather passed away fifteen years ago, I wanted to take advantage of this time and do something that would celebrate our relationship.

Before starting to work on our movies, we brought the objects to the classroom and shared their story with the others. We sat in a circle and exchanged about the objects, stories and ideas how to animate them. We could immediately see how our stories and objects connected as we were shared them, even though our relationships with them varied greatly. I could almost instantly relate to Dimitri’s object and his story. Like him, I had been growing up with limited opportunities to travel. So, it was through music and movies, that I had a window opened for me

\footnotetext{
${ }^{4}$ see: Marcel Proust (2001) A la recherche du temps perdu. Gallimard: Paris.
} 
to "the outside world". Sharing stories also provided a great source of new knowledge for me. One of the participants chose a gift she received while traveling to India. This led to a group conversation about Indian culture and traditions and gave me the chance to learn something new about this country.

Starting with the filming work, we were given complete freedom. The only instruction we received was to create a digital story based on the object we had chosen. There were no limits or restrictions when it came to how and what we wanted to show in our movies. This was both liberating and destabilizing. Liberating because I felt free and completely in control of my story. Destabilizing because of the high emotional and evocative load that my object was carrying. The multitude of events and stories that my bookmark had been involved in made it difficult to choose, develop and represent a storyline. I remember creating, cancelling and re-creating storyboards. Every time I thought that I had found the best solution, some new memory would come up and made me change my ideas. I felt that eventually I settled on a story that I wanted to tell, but, after starting to film, I ended up changing it again.

One of the most difficult decision was to create the set for my movie. At first, I considered doing it in the classroom, using white wallpaper as a background. Yet, this did not feel right. The bookmark spurred my interest and love for books, and I felt that it belonged in the middle of books. This is why I chose the new University library as a location for filming it. However, deciding on the perfect spot for my object within this space turned out to be more complicated than I thought. It felt like it was not just me working with the bookmark, but also the bookmark working with me. In the end, I had the impression that my object decided on its own what the best spot would be, which in turn influenced and changed my decisions. 
The intensity of emotions involved in the making of the movie has fluctuated during the process. One of the main reasons for this is the fact that the location I chose as a film set is frequented by many students during the day. This led to the activity of filming being very often interrupted by people passing by and stopping to enquire about the movie and the Summer School. Those were moments when I felt that the connection between me and my object was weaker and the intensity of emotions lower.

On the contrary, the part of the film that shows me learning the alphabet was the most intense in terms of emotions. This was mainly because it was filmed entirely in the classroom, and my engagement with the bookmark was not disturbed for the whole time I was working there. The intensity of emotions was amplified by the many memories connected to this particular moment. This was the moment when my hands were mechanically moving the bookmark and taking the photos, while my mind was wondering back to my grandparents' living room, to those winter evenings by the chimney where they would patiently show me every letter of both the Latin and the Cyrillic alphabet. At some points I could almost feel the smell of burned wood and mint tea that was so characteristic of my grandparents' house in wintertime and hear my grandfather's favourite compositor playing quietly on the record player. This was also the moment where I felt that I needed to use one of those songs as a background soundtrack for my movie.

The music was the last piece of the puzzle and, once added to the movie, I felt like my picture was complete. When assembled together, the bookmark, the books and the music made me relive some of the most vivid memories of my childhood.

To conclude I would say that, except for the fact that it was extremely enjoyable, this experience taught me many new things. First of all, I developed a higher level of empathy 
towards my colleagues. As we have all shared a similar path in making our movies and faced similar challenges, we grew to understand each other better and develop a deeper appreciation for each other's work.

Secondly, as I come from a long tradition of learning by following the instructions given to me, I learnt how to work, when there are no instructions at all. As I mentioned above, it was destabilizing at first, because I did not know where to start, or how to proceed. But, as time passed, I learned how to orient myself in a rule-free context, how to make my own decisions and how to trust in them.

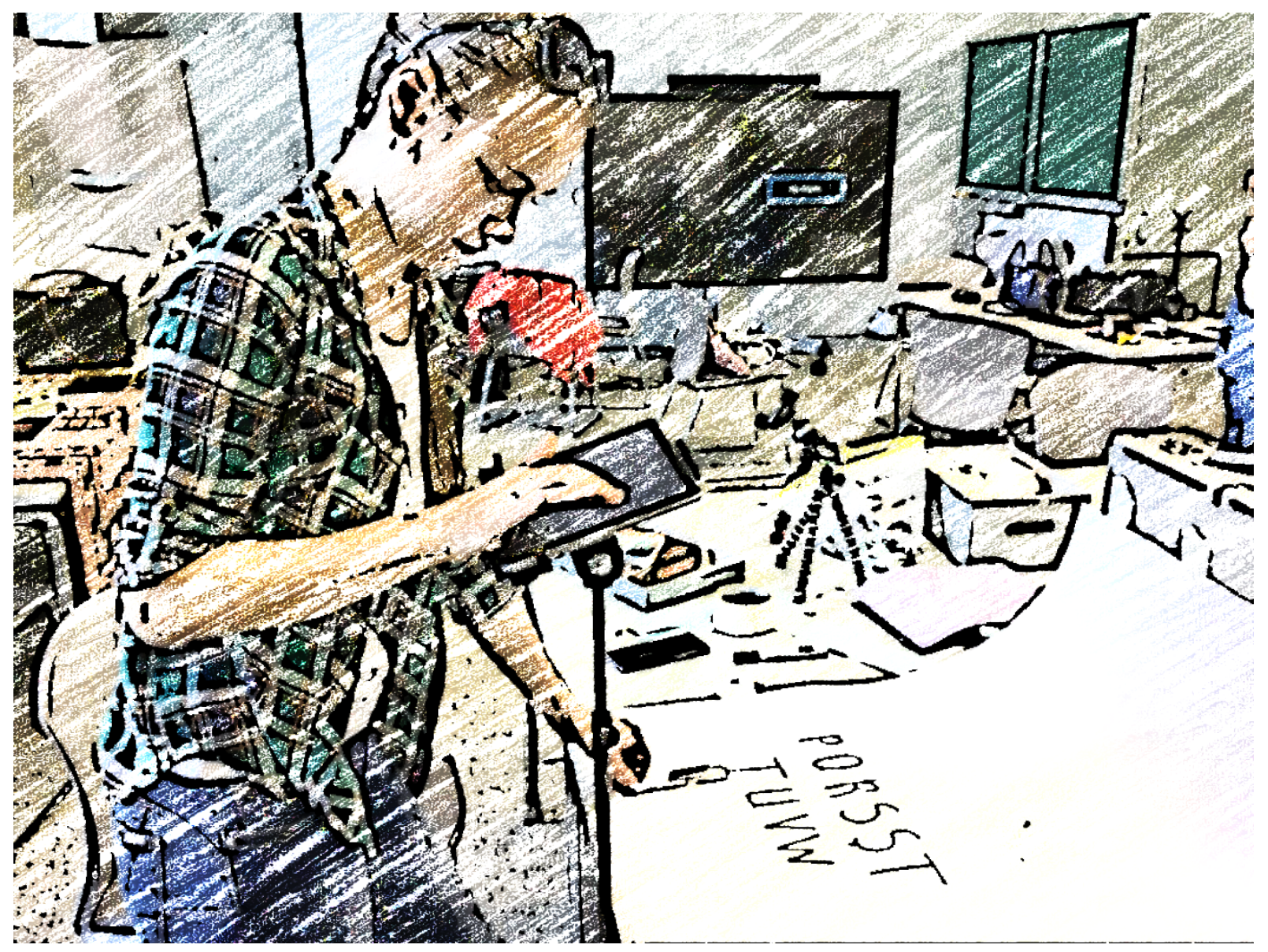

Image 2: Daniela and her bookmark learning how to read. To see her movie please got to:

https://vimeo.com/335557806 (enter password: affect2) 


\section{Gohar}

Looking back, my process of animation making unfolded in phases. These, however, did not emerge in a linear way. In fact, the whole making of the animation happened in a rather rizhomatic fashion. Saying this, I feel inspired by what Deleuze and Guattari (1987) refer to life as emergent, having no natural directions of growth or boundaries or barriers.

Initially, I was confronted with hesitation and uncertainty about the object I had to animate. I was not sure whether a carrot would provide me a lot of space and possibilities to work with and to tell as personal story through it. Little by little, my perspective changed as I tried to look beyond what I thought was a limit. I managed to overcome the boundaries that I had created, myself. What I did was to embrace the challenges and difficulties that seemed to be in my way, and hindering, and to invest myself in the creative space. The openness and flexibility of this kind of creative space was one of the most motivating factors, which I based my work on.

I spent a lot of time experimenting, repurposing and redefining the object I was working with. I had set myself the task to animate a carrot, a type of vegetable that had gained a certain significance for me at a certain point. It was that object, which had opened up a new understanding for me about the world in general and about my home country in particular. Consequently, the object started to gain an emotional connotation for me as well.

Hence, my goal became to put together the emotions and newly acquired meanings that the carrot carried for me now and tell them through a story. To achieve that, I had to go through an intensive process of repurposing. The carrot ceased to be a just a vegetable I used to cook or eat raw. It was no longer a product sitting on the counters of grocery stores. Moreover, throughout the process of working with it, the carrot kept transforming and changing. 
First, it started to obtain some sort of anthropomorphic features while I was playing with it. Of course, I arrived at this understanding later when I reflected back on my experience. It was only after I gave it a thorough thought that I realized the extent to which I was making the carrot behave in a human-like way. For instance, I made it have hands and feet, I made it 'unterhaken'5 with other carrots, I made it dance in order to express happiness, joy and excitement. On the whole, this kind of a contact with the carrot made me treat it as one of my own kind. At one point, we became one entity, as the film will show. Inspired by Lenz-Taguchi (2014), I feel that, in my experience, we both, the carrot and I, were holding and exercising agency and the capacity of transforming each other.

Second, I started to relate more and more to the carrot in the sense that my imagination went wild, and I totally integrated into the creative space and process. This integration manifested itself in all the ways I used the carrot in order to tell my story. I cut it into pieces, then into even smaller pieces, I grated the carrot, decomposing its boundaries and recomposing the material in new ways. Immersed in this doing, the boundary between bodies, the carrot and me, became invisible and less and less tangible.

Then, there was another aspect of the process creating physical contact, between me and the object. The haptic nature of animation making gave it another dimension - taking shot - after shot - after shot. I can refer to it as a meditative and contemplative process. It gave me a space for the body and the mind to be in harmony and balance. Each touch and movement were accompanied by a sensation, a feeling, an emotion. I was experiencing some sort of cleansing of

\footnotetext{
${ }^{5}$ The term 'underhaken' is German for ‘to link arms' in English. It emerged from one of our group discussions that happened in English, with neither of us being a first speaker of that language. No one could think of the term in English then, so (the author) suggested the German term and we stayed with it throughout our discussion, repeating the term and the moves it suggests, and sharing a lot of laughter and fun around 'unterhaken'.
} 
my mind and relaxation of my body while performing these constantly repetitive actions such as moving the object, pressing the button, placing the objects in a new position, pressing the button again, etc.

Feeling empty for some time while doing the moves, the process would then turn into some sort of reflective practice, developing into a chain of thoughts about myself. In this new dynamic starting to flow, I remember having asked myself a number of questions: why had I had chosen that object? What was I thinking now of carrots? Did it have a new meaning in my life? What was it? Through these questions, I was trying to understand things about myself. It was, in some sense, an exploration of my identity. Speaking with an image, I felt like on a hiking tour to a place where I had already been, but this time it was a different season and therefore the landscapes looked different as well.

Finally, what remains memorable for me is the screening of our animated films and the moment of sharing them with the other participants. After experiencing the role of an author and creator of a film myself, my perspective and relationship with the audience shifted dramatically. I saw personal stories; I saw the emotions of others, their memories, all while thinking about my own experience. All these spoke to me in a strong and more intimate way, since I could relate to them based on what I had been through myself. 


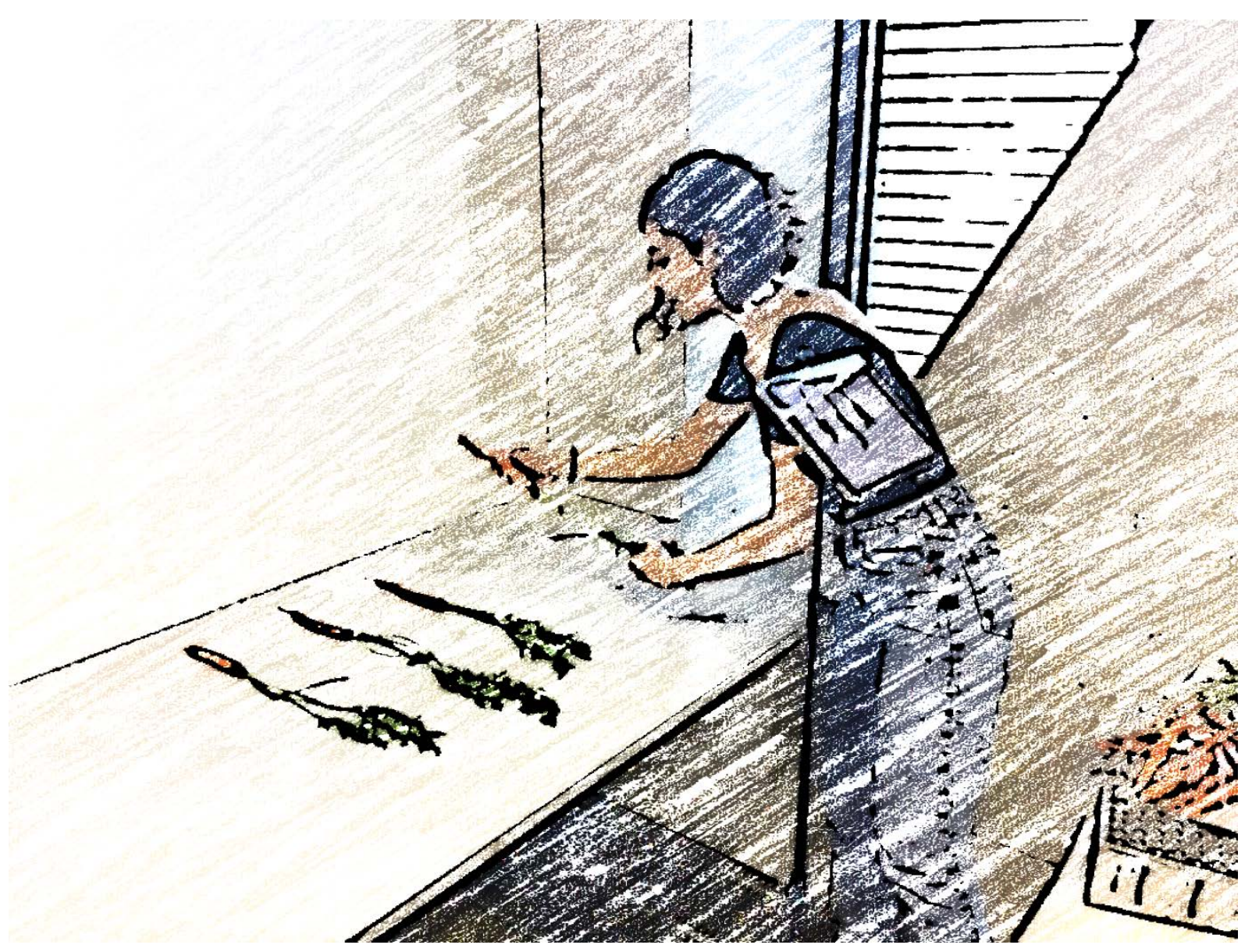

Image 3: Gohar exploring carrots. To see her movie please go to: https://vimeo.com/335567239 (enter password: affect3)

\section{Three 'Stories': A summary}

Three different stories, three different processes of becoming, starting from different points in an individual course of life and leading to different points at the end of the Summer School.

Ready to dive into something new, an experiment of creative process, Dimitri did not bring any plan or pre-meditated idea to the task. This seemed to ease for him establishing an affective relationship with things immediately at reach, the forming of an assemblage and the quick establishing of a workflow. Isolating himself from human contact, seemed to intensify 
communication with his objects, and not thinking or worrying about the result, but experiencing the process, seemed to help immersing himself and staying intensely immersed in the process.

Hoping to celebrate the relationship with her grandfather to whom Daniela feels strongly emotionally connected through her object, she brought a goal and pre-existing design, filled with memory, to the animation project. Carrying a complex, long-time experience to the animation stage turned out to be difficult, as memories and scripted ideas seemed to transform into animation work with difficulty. Expanding possibilities emerged from choosing a location outside of the classroom - the library - pushing the project and affective connection to intensify, as pieces of furniture suggested themselves into the assemblage. Other forces were pulling away from the project and decreasing the affective intensities sustaining it, as people disturbed the work by watching and asking questions. Noteworthy, the strongest connection and greatest affective intensity unfolded in the classroom, when, undisturbed, the most simple design, involving the bookmark and a few letters written on a piece of paper, created the scene. This happened to the end of the entire process, provoking a kind of synesthetic revival of childhood memories, filled with strong emotion, images and senses, smells and sounds.

An object of knowledge, rather than one of human bonding, was what Gohar brought to the task. Making sense of that connection and struggling with the affordances of her object, it took time for her to find her way into the assemblage, affective relationship and workflow. It seemed that exploring the object - and giving up on what it conventionally meant and was used for - began to open up new possibilities to connect and understand, about the world, her country and, ultimately, herself. It seemed that through the process of exploring, abandoning conventional meaning and repurposing, an emotional relationship began to grow that enabled her to ask new questions. Interestingly, swells followed ebbs of intensity; periods of emptiness gave 
way to periods of reflection, connecting body and mind in ways that enabled new perspectives and the revisiting of places where she had been, but that she could see now from a different viewpoint.

\section{Expanding the assemblage: Beginning to think with theories of affect}

Writing this text has been an experiment, both complex and expanding. It began with the Summer School, our first-hand experience of affect explored in this text. By this time, affect as a focal point of theoretical reflection was still unknown to us, the student co-authors. Together in the same classroom, we shared our stories and soon, as we began filming, a flow of energy - we now call affect - started floating through the assemblage of our individual project and those of our colleagues working next to us. At this stage, the experiment was about testing what creating movement and inter-acting with materials would do for us and how it would stimulate learning for us under these conditions.

The experiment and assemblage expanded when we decided to embark on a process of thinking and writing collectively about our experience. Reading and discussion about affect, we learnt a new language of description. Finding a way into the literature, we practiced what MacLure (2013) advises the qualitative researcher to do to get a fresh look at data, pointing out: “the value of an 'affective’ approach that can help slow us down and sit with what in the data sparks “fascination or exhilaration . . . incipience, suspense or intensity” (69). [She also suggests that qualitative researchers spend more time considering] data "hot spots"- those affective relations to data that both "disconcert" and create a sense of "wonder"where data "glows" for the researcher in various moments of fieldwork, analysis, and beyond (172-173) 
We highlighted these passages and prepared a selection of quotes, which we discussed in the next group meeting. This practice helped us to share our experience on a more reflective level and to understand terms such as 'assemblage', 'affect', and 'affective intensities'. Feeling an imprecise force of attraction at first, we gradually discovered deeper levels of meaning through our discussion and adopted the terms, gradually, as a new language of description that we appropriated as a way to talk about our experience. Dimitri felt attracted by quotes saying: “affect does not so much reflect or think; affect acts" (Freud 1966: 357-59), or “affect [is] the prime "interest" motivator that comes to put the drive in bodily drives" (Tomkins 1962, cited in Gregg \& Seighworth 2010: 6), and he pointed out that this was precisely what he felt during the animation making. Daniela felt very much attracted by a quote from Pahl and Rowsell (2011) saying that "artifacts give power to meaning makers" (134). She also felt very strongly about Turkle’s (2007) notion of 'evocative objects' which connected with the strong emotional connection and human relationship that her bookmark symbolized for her. Gohar, after her exploration, kept insisting on how much 'transformation' had been important for her, first transformation of her object and then transformation of herself, her relation to the object and the revealing of things 'not yet known' to her, that exploring the object had laid open. Her experience resonated strongly with Lenz-Taguchi (2014) who says, "both humans and objects hold the capacity of agency and co-constitutively transform each other" (cited in Thiel 2015: 115). Through the reading, we were able to distill dimension of the process that, we agreed, had become important for all during animation making. Working on the animation felt to be an intensive process. Being concentrated on an object, touching, handling, exploring, moving it over a long period of time created an unusual, and unusually intensive contact, that was, we believe, an important part of creating affect, in our context. We noted that the haptic, the 
prolonged physical engagement with one or more objects also had a strong - often soothing affective impact, similar to a deeply immersive and meditative practice. Even though the intensity of the experience varied across time, space and individuals, haptic engagement, we felt, was very fundamental for all of us. Two more dimensions we discussed and distilled as central in shaping individual experience of animation making, we the emotional and the impact of memory. We agreed that all three dimensions could have a shaping and driving force in the process, but that the haptic, the power of touch was the strongest in creating affect, for all of us.

\section{What we learnt from our experience and what we wish to share}

By sharing our experience, we wish to recommended animation making as a valuable experience to be lived by others too. We experienced affect as a force that stimulates learning through the deep and prolonged engagement with materials. Thinking about and in terms of affect taught us about the forces that may enhance or hinder motivation, exploration and experimentation, nurturing the flow of process or cutting us off from it. We learnt about the value of engaging in and giving oneself into an experimental process of which the outcome is not pre-designed. Experiencing this process has also taught us new ways of learning that decentered us from language, and linguistic, textual norms. Underlying expected ways of behaving built on monolithic ideas of monolinguism, they underlie most formal educational settings. These normative frames often hinder those who do not feel owning them to participate, belong, feel legitimate and dare to explore and express their potential and ideas to the full. In our Master program, we strive to build an environment where diversity is the norm and where diverse positioning has a room to be constructed and expressed. We feel that animation making can provide such a safe space inviting exploration, experimentation and the unfolding of the 
unknown. This is because animation making forces us to unlearn some of the rules of behavior demanded in monolithic systems we all have been educated in, and that we have embodied to a point that it may feel difficult or uneasy, at first, to unlearn them. In broader terms, we appreciated animation making as an approach that forced us, to a certain extent, to experiment with materials and to letting materials inter-act with us, experiencing the benefits of 'vital materialism', that, as Bennett (2010) says:

“...set(s) up a kind of safety net for those humans who are ... routinely made to suffer because they do not conform to a particular (Euro-American, bourgeois, theocentric, or other) model of personhood.” There was an "ethical aim [...] to distribute value more generously, to bodies and such.” (13)

Although, we don't think it is possible (or desirable) to teach affect, we believe in the possibility of creating conditions in which affect can emerge and thrive, giving space to 'life forces’ to unfold (Coleman \& Ringrose 2013, Hickey-Moody \& Malins 2007). Such spaces allow learners to explore the vital capacity of life, its agencements, and its potential for becoming (Wallin 2011). This should invite us to rethink curriculum in ways that consider and make space for learning that does away with determining pre-conceptions and happens in relations of immanence and in-between-ness. 'Life force' became tangible for us in animation making, most intensely, when objects took the lead, suggested the next move, providing the next fresh idea, behaving unruly or folding in the curve of the hand, blurring the fine line between human and object.

Second, we wish to recommend animation making as a terrain to introduce 'thinking with new materialist theories', with students, teacher and teacher trainees, as an alternative way to approaching curriculum design and learning. We can recommend our approach that began by 
engaging in firsthand experience, and then turned towards exploring, experimenting and thinking with an affect theory perspective. Having been rather eclectic in our choice of sources, we do not wish to suggest (another) affect theory, but rather to show how elements of theories of affect (in plural) resonated with our experience. The process helped us to understand more deeply the processes we lived through, while learning about movement and how animation making mobilizes the body and the mind, about the materiality of things, and how we connect with them. It also taught us to pay new and accrued attention to the environment, as it became part of the assemblage of our project. And finally, we learnt about ourselves, and what happened to us as we joined the assemblage, noticing, more or less consciously, how the process affected and, ultimately, changed us. Finally, we wish to say that none of the 14 participants in the Summer School had been left unaffected by the experience, and that all reported on the experience as intensive, powerful, empowering, liberating, and carrying intensity in some manner or fashion, deeply involving learning. We agree with Latour (2004) who says that learning happens best and only really — if it happens in the midst of affected bodies. "There is no life apart from the body, [then] to have a body is to learn to be affected, meaning 'effectuated: moved, put into motion by other entities, humans or nonhumans.” (205). Creating, thinking and building this piece of work together has been an exciting journey and a strong, bonding experience. Coming out of it, we feel invigorated, more knowledgeable and empathic towards our peers, after having experienced the process, its flow and affective intensities. Looking back, we wish to say, happily and proudly, "we have been there together." 


\section{References}

Barad, K. (2007). Meeting the universe halfway: Quantum physics and the entanglement of matter and meaning. Durham, NC: Duke University Press.

Bennett, J. (2010). Vibrant matter: A political ecology of things. Durham, NC: Duke University Press

Colbrook, C. (2002). Gilles Deleuze. New York, NY: Routledge.

Coleman, B., \& Ringrose, J. (2013). Deleuze and research methodologies. Edinburgh, UK: Edinburgh University Press.

Deleuze, G., \& Guattari, F. (1987). A thousand plateaus: Capitalism and schizophrenia (B. Massumi, Trans.). Minneapolis: University of Minnesota Press.

Freud, Sigmund (1957). "Mourning and Melancholia." In The Standard Edition of the Complete Psychological Works of Sigmund Freud, ed. and trans. James Strachey, 14: 237-58. London: Hogarth.

Gregg, M., \& Seigworth, G.J. (Eds.). (2010). The affect theory reader. Durham, NC: Duke University Press.

Halliday, M. A. K. (1978). Language as social semiotic. London, UK: Edward Arnold.

Halliday, M. A. K. and Matthiessen, Ch. M. I. M. (2014). Halliday’s Introduction to Functional Grammar (4 ${ }^{\text {th }}$ edition). London: Routledge.

Hickey-Moody, A., \& Malins, P. (2007). Deleuzian encounters: Studies in contemporary social issues. London, England: Palgrave.

Lankshear, C., \& Knobel, M. (2006). New literacies: Everyday practices and classroom learning (2nd ed.). Berkshire, UK: Open University Press. 
Latour, B. (2004). How to talk about the body? The normative dimension of science studies. Body \& society, 10(2-3), 205-229.

Leander, K., \& Boldt, G. (2013). Rereading “A Pedagogy of Multiliteracies”: Bodies, texts, and emergence. Journal of Literacy Research, 45(1), 22-46.

Lenz-Taguchi, H. (2014). New materialism and play. In L. Brooker, M. Blaise, \& S. Edwards. (Eds.), Sage handbook of play and learning in early childhood. London, England: Sage. 79-90.

MacLure, M. (2013). Classification or wonder? Coding as an analytic practice in qualitative research. In B. Coleman \& J. Ringrose (Eds.), Deleuze and research methodologies. Edinburgh, UK: Edinburgh University Press. 164-183.

Malins, P. (2004). Machinic assemblages: Deleuze, Guattari and an Ethico-aesthetics of drug use. Janus Head, 7, 84-104.

Massey, D. (2005). For space. Thousand Oaks, CA: Sage.

Massumi, B. (2002). Parables for the virtual: Movement, affect, sensation. Durham, NC: Duke University Press.

New London Group. (1996). A pedagogy of multiliteracies: Designing social futures. Harvard Educational Review, 66(1), 60-92.

Pahl, K. H., \& Rowsell, J. (2011). Artifactual Critical Literacy: A New Perspective for Literacy Education. Berkeley Review of Education, 2(2), 129-151.

Pratt, M. L. (1991). Arts of the contact zone. Profession, 33-40.

Roth, W.-M. (2017). Thinking with Spinoza about 'hands-on' learning. Educational Philosophy and Theory, 50(9), 839-848. 
Sedgwick, E. K., \& Frank, A. (1995). "Shame in the Cybernetic Fold: Reading Silvan Tomkins." In Shame and its Sisters: A Silvan Tomkins Reader, ed. E. K. Sedgwick and A. Frank, Durham, N.C.: Duke University Press. 1-28.

Spinoza, B. (1959). Ethics: On the Correction of Understanding. Trans. Andrew Boyle. London: Everyman's Library.

Thiel, J. J. (2015). Vibrant Matter: The Intra-Active Role of Objects in the Construction of Young Children’s Literacies. Literacy Research: Theory, Method, and Practice, 64(1), 112-131. https://doi.org/10.1177/2381336915617618

Tomkins, S. (1962). Affect, Imagery, and Consciousness: The Positive Affects. New York. Springer Publishing Company.

Turkle, S. (Ed.). (2007). Evocative objects: Things we think with. Cambridge, MA: MIT press.

Wallin, J. J. (2011). What is? Curriculum theorizing: For a people yet to come. Studies in Philosophy and Education, 30(3), 285-301. 